\title{
Assessment of respiratory muscle function
}

\author{
M. Decramer, G. Scano*
}

In the last two decades, respiratory muscle function in patients has received considerable attention, particularly since Roussos and MACKLEM [1] hypothesized that respiratory muscle fatigue may be responsible for the development of respiratory failure. Although subsequent research has hitherto largely failed to demonstrate the frequent occurrence of respiratory muscle fatigue [2], it is now clear that respiratory muscle weakness is present in many patients and that it represents a significant problem for various reasons [3]. Consequently, respiratory muscle function is frequently studied in patients, and a large variety of new techniques for examining respiratory muscle function have been developed in recent years. These techniques were reviewed in a postgraduate course on the occasion of the annual meeting of the European Respiratory Society in Florence, September 1993. The presentations of this postgraduate course form the basis of the present Review Series "Update on Respiratory Muscles".

Although maximal inspiratory and expiratory pressures represent simple measurements of respiratory muscle strength in patients [4], these measures are confronted by a number of problems, which limit the conclusions to be drawn from them. These predominantly include the fact that, occasionally, very low values may be due to inadequate effort by the patient. This consequently means that very low values are not always indicative of respiratory muscle weakness and that the scatter of normal values is relatively large [5]. To overcome this problem, several investigators have attempted to develop techniques not requiring patient co-operation. Essentially, two such techniques are presently available: electrical stimulation [6] and magnetic stimulation [7] of the phrenic nerves. The latter technique has the advantage of being entirely painless in contrast to the electrical stimulation, although it might provide diaphragmatic stimulation which is less specific [8]. The measurement of the mechanical outcome of contraction, however, remains to some extent problematic.

Indeed, adequate pressure measurement often still requires placement of an oesophageal or gastric balloon, or both. The placement of balloons is usually considered to be unpleasant by stable patients. In essence, two methods would allow this problem to be avoided. Firstly, measurement of mouth occlusion pressure during stimu-

Correspondence: M. Decramer, Respiratory Division, University Hospital, Herestraat 49, 3000 Leuven, Belgium. * Respiratory Muscle Research Unit, Laboratory of Pneumology, Katholieke Universiteit Leuven and Istituto Clinica Medica III, Universita degli Studi di Firenze, Italy. lation might provide a reasonable reflection of the pleural pressure generated. This is the case in normal subjects [9], but may be difficult in chronic obstructive pulmonary disease (COPD) patients, since the time constant of equilibration between alveolar pressure and mouth pressure in these patients appears to be relatively long [10]. Secondly, a highly interesting approach still under development is phonomyography, which is the measurement of the sound signal produced by diaphragmatic contraction [11]. This sound signal, which can be recorded noninvasively with surface microphones, appears to be directly proportional to the tension developed during contraction. Although the technique is still under study, it may well become the standard investigatory method of respiratory muscle strength.

The development of measures of respiratory muscle function independent of patient co-operation is of particular significance in patients in intensive care units who are unable to co-operate during measurements. Investigation of respiratory muscle function is all the more important in these patients, since they are regularly operating at the limit of their endurance capacity, and may well develop fatigue during failure of weaning [12]. Since development of respiratory muscle failure is expected to be dependent on the load, it is relevant to measure the load put on the respiratory muscles as well. This usually requires measurement of the fractional duration of contraction and the force developed during contraction as a fraction of the maximal force that may be developed [13].

Assessment of respiratory muscle function and activity also appears of great importance in patients under partial ventilatory support, since under modes of partial ventilatory support, such as synchronized intermittent mandatory ventilation, the work actually performed by the respiratory muscles is often considerably greater than expected [14]. Moreover, it appears poorly predictable from ventilator settings. By contrast, respiratory muscle rest seems to be better obtained by inspiratory pressure support [15]. Assessment of variations in inspiratory muscle work with alterations in settings of ventilators, thus, seem, to be relevant to understanding the load an individual patient faces during the weaning process.

Finally, another particular circumstance during which assessment of respiratory muscle function poses particular problems is assessment in infants. In newborns, the respiratory muscles are often stressed to the extreme limits of their endurance capacity [16]. The newborn may be considerably more frequently confronted with respiratory muscle fatigue than the adult. Thoracoabdominal motion in infants is disturbed, in the sense that 
thoracic motion is much smaller than in adults. This is likely to reflect the structural immaturity of the infant rib cage, leading to far greater distortibility than in adults [17].

It is striking that virtually all of the contributions to this Series deal with the assessment of respiratory muscle strength. There is little discussion on measures of respiratory muscle endurance, although clinically this endurance may be significant, particularly in producing ventilatory limitation during exercise [18]. Measures of respiratory muscle endurance have been developed [19-22], but the relevance in the clinical setting remains only partly understood.

Along these lines, although respiratory muscle weakness is now clearly identified as a prevalent and significant problem, the consequences of respiratory muscle weakness have only scantily been studied.

It appears likely that respiratory muscle weakness is associated with complaints such as dyspnoea [23]. Moreover, it may be related to exercise limitation [24]. In COPD patients [25] and in patients with neuromuscular disease [26], respiratory muscle weakness appears to be related to the development of respiratory failure. Some indication is present that it may be related to the use of health care facilities in COPD patients [27]. Finally, if patients with weak respiratory muscles are not as well able to cope with an increased load as patients with strong respiratory muscles, the former may also have reduced survival. Prospective studies critically assessing the relationship between respiratory muscle weakness and survival in COPD patients still need to be performed. If survival were to be related to respiratory muscle function, its assessment in patients would be all the more important.

\section{References}

1. Roussos C, Macklem PT. Diaphragmatic fatigue in man. J Appl Physiol: Respirat Environ Exercise Physiol 1977; 43: 189-197.

2. NHLBI Workshop. Respiratory muscle fatigue. Am Rev Respir Dis 1990; 142: 474-480.

3. Rochester DF. Respiratory muscle weakness, pattern of breathing, and $\mathrm{CO}_{2}$ retention in chronic obstructive pulmonary disease. Am Rev Respir Dis 1991; 143: 901-903.

4. Black LF, Hyatt RE. Maximal respiratory pressures: normal values and relationship to age and sex. Am Rev Respir Dis 1969; 99: 696-702.

5. Green M, Laroche CM. Respiratory muscle weakness. In: Brewis RAL, Gibson GJ, Geddes DM, eds. Respiratory Medicine. Baillière Tindall, 1990; pp. 1373-1387.

6. Bellemare F, Bigland-Ritchie B. Assessment of human diaphragm strength and activation using phrenic nerve stimulation. Respir Physiol 1984; 58: 263-277.

7. Similowski T, Fleury B, Launois S, Cathala HP, Bouche P, Derenne JP. Cervical magnetic stimulation: a new painless method for bilateral phrenic nerve stimulation in conscious humans. J Appl Physiol 1989; 67: 1311-1318.

8. Wragg S, Aguilina R, Goldstone J, Green M, Moxham J. Cervical magnetic stimulation of the phrenic nerves. Eur Respir J 1991; 4 (Suppl. 4): 309S.
9. Yan S, Gauthier AP, Similowski T, Macklem PT, Bellemare F. Evaluation of human diaphragm contractility using mouth pressure twitches. Am Rev Respir Dis 1992; 145: 1064-1069.

10. Similowski T, Gauthier AP, Yan S, Macklem PT, Bellemare F. Assessment of diaphragm function using mouth pressure twitches in chronic obstructive pulmonary disease patients. Am Rev Respir Dis 1993; 147: 850-856.

11. Similowski T, Petitjean MB, Maton B, Monod H, Derenne JP. Phonomyogram of the diaphragm during phrenic stimulation and sniff test. Am Rev Respir Dis 1992; 145: A255.

12. Cohen C, Zagelbaum G, Gross D, Roussos C, Macklem PT. Clinical manifestations of inspiratory muscle fatigue. Am J Med 1982; 73: 308-316.

13. Goldstone JC, Green M, Moxham J. Maximum relaxation rate of human diaphragm during weaning from mechanical ventilation. Thorax 1994; 49: 54-60.

14. Marini JJ, Smith TC, Lamb VJ. External work output and force generation during synchronized intermittent mechanical ventilation. Am Rev Respir Dis 1988; 138: 1169-1179.

15. Brochard L, Harf A, Lorino H, Lemaire F. Inspiratory pressure support prevents diaphragmatic fatigue during weaning from mechanical ventilation. Am Rev Respir Dis 1989; 139: 513-521.

16. Milic-Emili J. Respiratory muscle fatigue and its implications in RDS. In: Cosmi EV, Scarpelli EM, eds. Pulmonary Surfactant System. Elsevier Science Publishers B.V., 1983; pp. 135-141.

17. Hershenson MD, Colin M, Wohl MEB, Stark AR. Change in the contribution of the rib cage to total breathing during infancy. Am Rev Respir Dis 1990; 141: 922-925.

18. Pardy RL, Rivington RN, Despas PJ, Macklem PT. The effects of inspiratory muscle training on exercise performance in chronic airflow limitation. Am Rev Respir Dis 1981; 123: 426-433.

19. Leith DE, Bradley ME. Ventilatory muscle strength and endurance training. J Appl Physiol 1976; 41: 508-516.

20. Belman MJ, Mittman C. Ventilatory muscle training improves exercise capacity in chronic obstructive pulmonary disease patients. Am Rev Respir Dis 1980; 121: 273-280.

21. Nickerson BC, Keens TG. Measuring ventilatory muscle endurance in humans as sustainable inspiratory pressure. J Appl Physiol: Respirat Environ Exercise Physiol 1982; 52: 768-772.

22 McKenzie DC, Gandevia SC. Strength and endurance of inspiratory, expiratory, and limb muscles in asthma. Am Rev Respir Dis 1986; 134: 999-1004.

23. Killian KJ, Jones NL. Respiratory muscles and dyspnea. Clin Chest Med 1988; 9: 237-248.

24. Wijkstra PJ, Ten Vergert EM, van der Mark TW, et al. Relation of lung function, maximal inspiratory pressure, dyspnoea, and quality of life with exercise capacity in patients with chronic obstructive pulmonary disease. Thorax 1994; 49: 468-472.

25. Begin P, Grassino A. Inspiratory muscle dysfunction and chronic hypercapnia in chronic obstructive pulmonary disease. Am Rev Respir Dis 1991; 143: 905-912.

26. Braun NMT, Arora NS, Rochester DF. Respiratory muscle and pulmonary function in polymyositis and other proximal myopathies. Thorax 1983; 38: 616-623.

27. Decramer M, Gosselink H, Verschueren M, Demuynck $\mathrm{K}$, Evers G. Medical consumption is related to muscle weakness in COPD patients. Am J Respir Crit Care Med 1994; 149: A140. 